\title{
Flower diversity and bee reproduction in an arid ecosystem
}

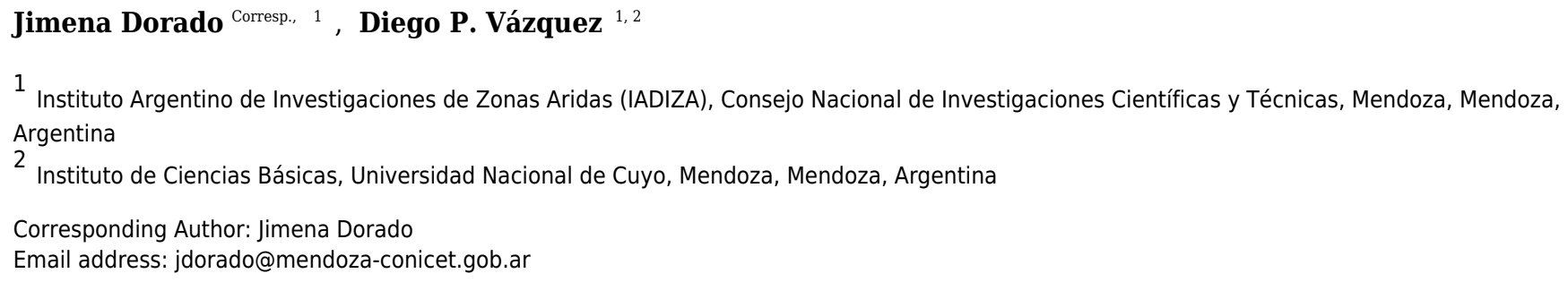

Background. Diverse flower communities are more stable in floral resource production along the flowering season, but the question about how the diversity and stability of resources affect pollinator reproduction remains open. High plant diversity could favor short foraging trips, which in turn would enhance bee fitness. In addition to plant diversity, greater temporal stability of floral resources in diverse communities could favor pollinator fitness because such communities are likely to occupy the phenological space more broadly, increasing floral availability for pollinators throughout the season. In addition, this potential effect of flower diversity on bee reproduction could be stronger for generalist pollinators because they can use a broader floral spectrum. Based on above arguments we predicted that pollinator reproduction would be positively correlated to flower diversity, and to temporal stability in flower production, and that this relationship would be stronger for the most generalized pollinator species. Materials \& Methods. Using structural equation models, we evaluated the effect of these variables and other ecological factors on three estimates of bee reproduction (average number of brood cells per nest per site, total number of brood cells per site, and total number of nests per site), and whether such effects were modulated by bee generalization on floral resources. Results. Contrary to our expectations, flower diversity had no effect on bee reproduction, stability in flower production had a weakly negative effect on one of the bee reproductive variables, and the strength of the fitness-diversity relationship was unrelated to bee generalization. In contrast, elevation had a negative effect on bee reproduction, despite the narrow elevation range encompassed by our sites. Discussion. Flower diversity did not affect the reproduction of the solitary bees studied here. This result could stem from the context dependence of the diversity-stability relationship, given that elevation had a positive effect on flower diversity but a negative effect on bee reproduction. Although high temporal stability in flower production is expected to enhance pollinator reproduction, in our study it had a weakly negative---instead of positive---effect on the average number of brood cells per nest. Other environmental factors that vary with elevation could influence bee 
reproduction. Our study focused on a small group of closely-related bee species, which cautions against generalization of our findings to other groups of pollinators. More studies are clearly needed to assess the extent to which pollinator demography is influenced by the diversity of floral resources. 
1 Flower diversity and bee reproduction in an arid ecosystem.

2 Jimena Dorado ${ }^{1, *}$ and Diego P. Vázquez ${ }^{1,2}$

3

41 Instituto de Argentino de Investigaciones de las Zonas Áridas, CONICET, CC 507, 5500

5 Mendoza, Argentina.

62 Instituto de Ciencias Básicas, Universidad Nacional de Cuyo, Centro Universitario,

7 M5502JMA Mendoza, Argentina.

8 * E-mail: jdorado@mendoza-conicet.gov.ar; fax: +54-261-524-4101. 
9 Abstract

10 Background. Diverse flower communities are more stable in floral resource production along

11 the flowering season, but the question about how the diversity and stability of resources affect

12 pollinator reproduction remains open. High plant diversity could favor short foraging trips,

13 which in turn would enhance bee fitness. In addition to plant diversity, greater temporal stability

14 of floral resources in diverse communities could favor pollinator fitness because such

15 communities are likely to occupy the phenological space more broadly, increasing floral

16 availability for pollinators throughout the season. In addition, this potential effect of flower

17 diversity on bee reproduction could be stronger for generalist pollinators because they can use a

18 broader floral spectrum. Based on above arguments we predicted that pollinator reproduction

19 would be positively correlated to flower diversity, and to temporal stability in flower production,

20 and that this relationship would be stronger for the most generalized pollinator species.

21 Materials \& Methods. Using structural equation models, we evaluated the effect of these

22 variables and other ecological factors on three estimates of bee reproduction (average number of

23 brood cells per nest per site, total number of brood cells per site, and total number of nests per

24 site), and whether such effects were modulated by bee generalization on floral resources.

25 Results. Contrary to our expectations, flower diversity had no effect on bee reproduction,

26 stability in flower production had a weakly negative effect on one of the bee reproductive

27 variables, and the strength of the fitness-diversity relationship was unrelated to bee

28 generalization. In contrast, elevation had a negative effect on bee reproduction, despite the

29 narrow elevation range encompassed by our sites. Discussion. Flower diversity did not affect the

30 reproduction of the solitary bees studied here. This result could stem from the context

31 dependence of the diversity-stability relationship, given that elevation had a positive effect on 
32 flower diversity but a negative effect on bee reproduction. Although high temporal stability in

33 flower production is expected to enhance pollinator reproduction, in our study it had a weakly

34 negative---instead of positive---effect on the average number of brood cells per nest. Other

35 environmental factors that vary with elevation could influence bee reproduction. Our study

36 focused on a small group of closely-related bee species, which cautions against generalization of

37 our findings to other groups of pollinators. More studies are clearly needed to assess the extent to

38 which pollinator demography is influenced by the diversity of floral resources. 


\section{Introduction}

40 There is a consensus that diversity enhances ecosystem functioning (Cardinale et al. 2012).

41 Species diversity provides redundancy in function so that ecological processes are more stable in 42 more diverse communities (MacArthur 1955, Elton 1958). In plant communities, the diversity43 stability relationship has been well studied for biomass production (Caldeira et al. 2005, Tilman,

44 Reich \& Knops 2006, Isbell et al. 2009, Hector et al. 2010), and we have recently reported that

45 diverse flower communities are also more temporally stable in terms of floral resource

46 production (Dorado \& Vázquez 2014). But the question about how the diversity and stability of

47 resources affect reproduction of pollinators remains open.

49 It is well known that ecosystem productivity is positively associated to species diversity

50 (Cardinale et al. 2012). We propose that a similar effect of plant species diversity can be

51 expected on population- and community-level productivity of pollinators (i.e., reproductive

52 output or biomass), for several reasons. First, the probability that a resource species important for

53 reproduction is present increases with species diversity (the "sampling effect"; Loreau 2010).

54 Second, greater plant diversity can lead to reduced foraging trip duration (e.g., Gathmann \&

55 Tcharntke 2002), which could mean more energy available for reproduction (Minckley et al.

56 1994; Zurbuch et al. 2010). Third, if different plant species in the community offer

57 complementary resources (e.g., they cover non-overlapping nutritional needs of pollinators),

58 greater plant diversity could mean a greater probability of meeting the nutritional needs of

59 pollinators (see, e.g., Williams \& Tepedino 2003). The effect of flower diversity on bee

60 reproduction should be stronger for polylectic than oligolectic pollinators, given that the latter

61 are more restricted in their diet. 
62

63 In addition to plant diversity, greater temporal stability of floral resources in diverse communities (Dorado \& Vázquez 2014) could favor pollinator fitness because such communities are likely to occupy the phenological space more broadly than their species-poor counterparts, increasing floral availability for pollinators throughout the season. For example, in multi-species assemblages of herbaceous plants of the genus Clarkia, diverse communities provide more resources along the flowering season, sustaining a higher number of pollinator individuals per plant (Moeller 2004). Furthermore, a bumblebee study found that even if floral resources are abundant, high stability of floral resources throughout the flowering season is needed to enhance bumblebee fitness (Wesphal et al. 2009, Rundlöf et al. 2014). Thus, both high flower abundance and high temporal stability of floral resources are likely to enhance pollinator reproduction

73 (Müller et al. 2006, Westphal, Steffan-Dewenter, \& Tscharntke 2009).

To evaluate whether there is an effect of flower diversity on pollinator reproduction it is necessary to disentangle the effect of flower abundance, as it could be positively correlated with flower richness, as it happens with biomass in plant communities (Tilman 1999); if so, there could be a spurious positive correlation between flower richness and pollinator fitness. Other local environmental factors, such as elevation or disturbance history, should also be accounted for, as they are known to influence species diversity (Potts et al. 2003, Grytnes and McCain 81 2007, Dorado \& Vázquez 2014). Structural equation modeling (SEM) represents an excellent

82 tool to assess causal relationships among multiple variables simultaneously (Grace 2006), as is 83 the case in the present study. 
85 Our aim is to study the effect of flower diversity and temporal stability of floral resources on the

86 reproduction of a cavity nesting bee assemblage from the Monte desert in Argentina. Based on

87 the above arguments, we expected to find that flower diversity and temporal stability of floral

88 resources correlates positively to three estimates of bee reproduction at the population and

89 community levels: average number of brood cells per nest per site, total number of brood cells

90 per site, and total number of nests per site. We also expected to find a positive correlation

91 between the strength of the reproductive output-diversity correlation and the degree of

92 generalization of each bee species.

93

94 Methods

95 Study area and sampling

96 This study was conducted in the Monte desert in Villavicencio Nature Reserve, located ca. 40

$97 \mathrm{~km}$ north of Mendoza city, Argentina, during the 2008 flowering season (15 October -8

98 December 2008; authorized by Dirección de Recursos Naturales Renovables de la Provincia de

99 Mendoza, approval numbers 1130 and 646). We worked in fourteen $100 \mathrm{~m} \times 200 \mathrm{~m}$ rectangular

100 study sites (minimum and maximum distance between them were $1.11 \mathrm{~km}$ and $14.13 \mathrm{~km}$

101 respectively). These sites lie at 1100-1500 m above sea level, at the ecotone between the Monte

102 desert and the Prepuna biomes (Ambrosetti et al. 1986). The plant community is a $2 \mathrm{~m}$ tall

103 shrubland dominated by Larrea divaricata (Zygophyllaceae), Zuccagnia punctata (Fabaceae),

104 Prosopis flexuosa (Fabaceae), Condalia microphylla (Rhamnaceae), Acantholippia seriphioides

105 (Verbenaceae), and Opuntia sulphurea (Cactaceae). We selected sites with different flower

106 abundance, composition and diversity. The region suffers from recurrent fires, which are mostly

107 human-caused and are in fact the most common human disturbance (E. L. Stevani, pers. comm.); 
108 the time elapsed since the last fire varied substantially among our study sites (Table S1).

109

110 Trap nest sampling

111 We placed trap nests in 6 points per plot as shown in Fig. S1. Each point had two groups of 24

112 trap nests consisting of a wood piece with a longitudinal cavity of $5 \mathrm{~mm}, 8 \mathrm{~mm}$ or $11 \mathrm{~mm}$ in

113 diameter, and $15 \mathrm{~cm}$ of length for the smallest two diameters and $28 \mathrm{~cm}$ of length for the largest

114 diameter; wood pieces were arranged as shown in Fig. S2. Trap nests were checked weekly;

115 occupied traps were taken to the laboratory and replaced by empty ones. Each trap nest

116 constitutes one bee nest. Once in the laboratory, nests were opened to record the number of cells;

117 whenever the nest had more than one brood cell, one of them was extracted for pollen

118 identification for other analysis (Dorado et. al 2011, Vázquez et. al 2012), and the rest was kept

119 until adult emergence. The number of emerged adults and their taxonomic identity were recorded

120 in all nests. Although adult number may be a good estimator of female fitness in the absence of

121 larval mortality, because of the high rate of nest parasitism recorded in our study we used instead

122 the number of brood cells per nest as an estimate of female fitness. One species, Trichothurgus

123 laticeps Friese, lacks brood cells, as females lay eggs bare amidst a pollen mass; thus, for this

124 species we used the length of the trap cavity occupied by pollen as an estimate of the number of

125 brood cells. For the analysis, we used only the seven bee species that occupied at least 30 trap

126 nests, as we judged smaller sample sizes unreliable for statistical analyses.

128 Plant sampling

129 Floral resource availability was studied using flower density, as flowers represent the resources

130 packages encountered by pollinators as they forage (see also Vázquez et al. 2009). Flower 
131 density was measured weekly at four $8 \mathrm{~m} \times 20 \mathrm{~m}$ plots and two $2 \mathrm{~m} \times 50 \mathrm{~m}$ transects per site, as

132 described in Fig. S1. We considered weekly sampling intervals adequate, as flowers in our

133 system usually last less than a week. Flower density was estimated multiplying the mean number

134 of flowers per individual by the total number of flowering individuals in the transect or plot

135 when individuals could be distinguished (shrubs and some herbs); we estimated the number of

136 flowers per individual in at least ten individuals of the site. When it was not possible to identify

137 flowering individuals (some herbaceous species), all flowers in a plot or transect were counted.

138 We included in the study all flowering plant species that were assumed to be animal pollinated

139 (we excluded only grass species).

140

141 Statistical analysis

142 To evaluate the effects of flower diversity and temporal stability of floral resources on bee

143 fitness and to assess the influence of other ecological factors on this relationship, we used

144 structural equation models (hereafter SEM). We built a general initial model to explore the

145 effects of flower richness, flower abundance, time elapsed since the last fire, elevation, and

146 temporal stability in flower production on bee reproductive parameters. We estimated bee

147 productivity at the community level using two proxies: total number of brood cells per site, and

148 total number of nests per site. To evaluate reproduction at the species level we used three

149 proxies: average number of brood cells per nest, total number of brood cells per site, and total

150 number of nests per site. To estimate the average number of brood cells per nest we used only

151 data of sites where species were present; for the total number of brood cells per site and the total

152 number of nests per site we used data of all sites, as the absence of a species in a site represented

153 zero abundance. Flower richness was used as a proxy of flower diversity; it was rarefied to 
154 remove the effect of flower abundance. Flower abundance was estimated as flower density per

155 site. Time elapsed since the last fire was provided by park rangers (E. L. Stevani, personal

156 communication). Temporal stability in flower production along the season was calculated as the

157 inverse of its coefficient of variation (see Dorado \& Vázquez 2014). For each bee species, from

158 the initial model we generated more parsimonious nested models by removing variables with

159 small non-significant path coefficients (see models in Fig. 1; see also Maestre et al. 2010).

160

161 We evaluated alternative SEM models using a d-separation test (Shipley 2000, 2013). This

162 analysis allowed us to select the best fitting model based on Akaike's information criterion

163 (AIC) using a small sampling size. The d-separation test involves calculating a probability of

164 independence, $p_{i}$, between two pairs of variables that are not directly connected with an arrow in

165 the causal model, and then using those probabilities to calculate Fisher's $C$ statistic, which

166 follows a chi-square distribution, ${ }^{\mathrm{C}=-2} \sum_{\mathrm{i}=1}^{\mathrm{k}}\left(\ln \mathrm{p}_{\mathrm{i}}\right)$ (Shipley 2000, 2013). The group of all $k$ pairs

167 of independent variables with their corresponding conditional variables constitutes the basis set

168 (Table S2). Independence probability should be estimated using an appropriate test; in our case

169 we used the $p$-value associated to Pearson's partial correlation coefficient as an estimate of $p_{i}$.

170 We then calculated the maximum likelihood estimate for each model using the $C$ value

171 associated to each causal model, and the corrected Akaike's Information Criterion as AIC $=2 \ln$

$172 C+2 K$, where $K$ is the total number of free parameters in the model and $n$ is the sample size. To

173 discriminate among competing models we used the AIC difference, $\triangle \mathrm{AIC}$, between a given

174 model and the best-fitting one, i.e., that with the lowest value of AIC. When $\Delta \mathrm{AIC}<3$, models

175 are generally considered to have substantial support; for $3>\Delta \mathrm{AIC}<7$. models are considered to

176 have considerably less support, while for $\Delta \mathrm{AIC}>10$, models have essentially no support relative 
177 to the best model of the set (Richards 2005, Burnham \& Anderson 2010). We used meta-

178 analytical methods to evaluate whether the studied effects were general for all bee species. To

179 perform the meta-analytical methods, the path coefficients from the SEM models for each bee

180 species were normalized by applying Fisher's z transform, $z=0.5 \ln [(1+r) /(1-r)]($ Zar 1999$)$ to

181 make them comparable. To weigh the correlation coefficients, we divided them by the inverse of

182 the sampling variance, $w=1 / \operatorname{var}(r)=N-3$ (Rosenthal 1991; Zar 1999; Gurevitch et al. 2001).

183 We used a bootstrap resampling procedure written in R (R Core Team 2013), with a sample size

184 of 100000 , with which we calculated the mean and $95 \%$ percentile confidence limits of $z_{w}$

185 (Manly 1997).

186

187 To evaluate whether the effect of flower diversity becomes stronger with increasing pollinator

188 generalization, we performed Spearman's rank correlations between the path coefficient

189 representing the effect of flower richness on each of the three bee reproductive parameters

190 mentioned above, and two measures of the corresponding species degree of generalization. We

191 estimated the degree of diet generalization of each bee species using the species degree and

192 Simpson's diversity index; degree is simply the number of food species consumed from all sites

193 polled, whereas Simpson's index is a function of the number of food items and the proportion in

194 which they were consumed. We used rarefaction to estimate both measures of generalization to

195 make them comparable among bee species, as the number of brood cells was highly variable

196 among nests. A positive correlation between the path coefficient of flower richness on bee

197 reproduction and generalization would support our hypothesis that the reproduction of generalist

198 pollinators is enhanced by flower richness.

199 
200 All analyses were performed using R statistical software (R Core Team 2013). Rarefaction of

201 flower richness was performed using the rarefy function of the vegan package (Oksanen et al.

202 2013). Pearson's partial correlations were performed using the pcor.test function of the ppcor

203 package to obtain independence probabilities and the path coefficients (Kim and Yi 2007, Kim \&

204 Yi 2006, Johnson \& Dean 2002).

205

206 Results

207 We recorded 598 occupied trap nests by 11 solitary bee species (Table 1).

208

209 The complete model assessing the influence of multiple ecological factors on the potential

210 relationship between flower diversity and bee reproduction at a community level (Model 1, Fig.

211 1a) showed a negative effect of elevation on bee reproductive variables, and no effect of the

212 other evaluated factors on bee reproduction (Table 2).

213

214 The complete model assessing the influence of multiple ecological factors on the potential

215 relationship between flower diversity and each bee species fitness (Model 1, Fig. 1a) showed no

216 effect of flower abundance or time elapsed since the last fire on the bee reproductive variables

217 studied. Although the only significant effect was that of temporal stability on the average

218 number of brood cells per nest, we kept flower richness and elevation in the simplified model

219 because they showed suggestive, albeit non significant, trends. There was a weak positive effect

220 of flower richness on average number of brood cells per nest and a weak negative effect of

221 elevation on the three reproductive variables (Fig. S3); however, none of these effects were

222 statistically significant. The simplified model (model 2, Fig. 1b) fitted best according to $\Delta$ AIC 
223 (8.43) for all species (see S1 and Fig. 1); this model fits the data well according to the d-

224 separation test $(p=0.84, d f=2, C=3.69)$. In this simplified model, the negative effect of

225 temporal stability in flower production on the average number of cells per nest was weaker than

226 in the complete model (Fig. 2 blue error bars; confidence limits of path coefficient for model 1: -

$2270.467,-0.101$; confidence limits of path coefficient of model 2: $-0.264,-0.004)$. Also, the

228 simplified model shows a negative trend in the effect of elevation on the total number of cells

229 and nests per site, but this trend is statistically non significant (confidence limits of path

230 coefficients for the total number of cells and nests per site respectively: $-0.465,0.031$, and -

$2310.472,0.027)$.

232

233 The effect of flower diversity on pollinator reproduction was unrelated to pollinator

234 generalization for any of the bee reproductive variables and generalization indexes used (Table $2353)$.

236

237 Discussion

238 Contrary to our expectations, we found no effects of flower diversity and flower abundance on

239 bee reproduction, either at the community or at the species level. Thus, flower diversity did not

240 matter for the reproduction of the solitary bees studied here. Considering the ecosystem

241 functioning context where relationships are commonly saturating (Cardinale et al. 2012), there is

242 a possibility that we have sampled plant diversities corresponding only to the saturating part of

243 the diversity-productivity curve. In addition, this result could stem from the context dependence

244 of the diversity-stability relationship (Griffin et al. 2010), given that elevation had a positive

245 effect on flower diversity (Dorado and Vazquez 2014) but a negative effect on bee reproduction 
246 (Table 2). This trend in the effect of elevation on bee reproduction was observed despite the

247 narrow elevation range encompassed by our sites $(1100-1500 \mathrm{~m})$, which suggests that the

248 environmental conditions of the study sites could have influenced the relationship between floral

249 diversity and bee reproduction.

250

251 An explanation of the negative effect of temporal stability on brood cell production concerns a

252 compensatory behavior of females to avoid parasitism. In sites with high temporal stability in

253 flower production, females might lay fewer eggs per nest while building more nests, so as to

254 maximize larval survival per site. This reasoning makes two implicit assumptions. First, that the

255 bee species are parasitized, which we indeed observed for many of the bee species studied here.

256 Second, that nesting sites are not limited for the population. In fact, the trap nest sampling with

257 replacement highly increased the nest availability in our study sites. If this mechanism were

258 responsible for the observed negative effect of temporal stability in flower production on the

259 average number of brood cells per nest, we would expect the number of cells per site to be either

260 unrelated to temporal stability or to be higher in the more temporally stable sites, and the number

261 of nests to be higher in the more temporally stable sites, as females would be laying eggs at their

262 maximum capacity but distributing them in more nests. Matching these expectations, the total

263 number of brood cells per site was unrelated to temporal stability (Fig. 2, flower stability), while

264 the number of nests per site tends to increase with temporal stability for most species, although

265 the effect was statistically non-significant.

266

267 An alternative explanation of the negative effect of temporal stability on brood cell production

268 per nest could be that elevation might be weakening the effects of other variables on pollinator 
269 reproduction. This is particularly likely considering the positive direct effect of elevation on

270 flower diversity, the positive indirect effect of elevation on stability, and the negative effect of

271 elevation on bee reproduction (Table 2 and Fig. 2); these effects could be neutralizing the effect

272 of the flower diversity and temporal stability in flower production on bee reproduction. The

273 upper sites are located at the mouth of ravines, which are probably wetter and cooler than the

274 lower sites, located in open land. Thus, changes in humidity and temperature associated to

275 elevation could be influencing bee reproduction more strongly than the other ecological factors

276 studied here.

277

278 We found no support for the idea that generalist bees are more favored in their reproduction by

279 flower diversity than specialized ones, despite bee species included in this study having

280 contrasting degrees of feeding specialization. Again, we think the negative effect of elevation on

281 bee reproduction can be responsible for this unexpected result. It seems reasonable to think that

282 species will respond idiosyncratically to flower diversity and stability when there is context

283 dependency, given our finding of no general effects of flower diversity on bee reproduction.

285 Although there is a consensus that diversity promotes ecosystem-level productivity (Cardinale et 286 al. 2012), we failed to find this relationship at the community and population levels in our study.

287 But we bear in mind that our study focused on a small group of closely-related bee species, 288 representing less than 5\% of the pollinator assemblage in our study area (Chacoff et. al 2012).

289 Our study is in this sense limited, and our finding of no effects of floral diversity on pollinator

290 demography cannot be generalized. More studies are clearly needed to assess the extent to which

291 pollinator demography is influenced by the diversity of floral resources. These studies are 
292 becoming priority, as wild bees are known to enhance fruit production in crops, beyond the

293 pollination service provided by honeybees (Garibaldi et al. 2013). Furthermore, although we

294 have considered environmental factors, such as elevation or time post-fire, which appeared a

295 priori good candidates to influence bee demography, other environmental factors may also be

296 important. These include humidity and temperature, which should covary with elevation, and

297 other biotic factors such as competition, predation and parasitism.

298

299 Acknowledgements

300 We thank the administration of Villavicencio Natural Reserve for permission to conduct this

301 study, the park rangers for help to find appropriated study sites in the field, Arturo Roig for help

302 with bee identifications, Leticia Escudero, Nydia Vitale and Georgina Amico for laboratory

303 assistance, and members of the Ecological Interactions Lab for helpful comments on the

304 manuscript. JD is a postdoctoral fellow and DPV a career researcher with CONICET.

305

306

References

307 Blaauw, B. R., Isaacs, R. 2014. Flower plantings increase wild bee abundance and the

308 pollination services provided to a pollination-dependent crop. Journal of Applied Ecology

$309 \quad 51,809-898$.

310 Burnham, K. P., and Anderson, D. R. 2010. Model selection and multimodel inference. A

311 practical information - theoretic approach $2^{\text {nd }}$ ed.). New York: Springer.

312 Caldeira, M. C., A. Hector, M. Loreau, and J. S. pereira. 2005. Species richness, temporal

313 variability and resistance of biomass production in a Mediterranean grassland. Oikos 110, 115-

314123. 
315 Cardinale, B. J., J. E. Duffy, A. Gonzalez, D. U. Hooper, C. Perrings, P. Venail, A. Narwani1, G.

316 M. Mace, D. Tilman, D. A.Wardle, A. P. Kinzig, G. C. Daily, M. Loreau, J. B. Grace, A.

317 Larigauderie, D. S. Srivastava \& S. Naeem. 2012. Biodiversity loss and its impact on humanity.

318 Nature, 486, 59-67.

319 Chacoff, N. P., D. P. Vázquez, S. B. Lomáscolo, E. L. Stevani, and B. Padrón. 2012. Evaluating 320 sampling completeness in a desert plant-pollinator network. Journal of Animal Ecology $321 \quad 81,190-200$.

322 Dorado, J. and Vázquez, D. P. 2014. The diversity-stability relationship in floral production. $323 \quad$ Oikos $123,1137-1143$.

324 Dorado, J., D. P. Vázquez, E. L. Stevani, and N. P. Chacoff. 2011. Rareness and specialization 325 in plant-pollination networks. Ecology 92, 19-25.

326 Elton, C. S. 1958. Ecology of invasions by animals ans plants. With a New Foreward by Daniel 327 Simberloff 2000. University of Chicago Press.

328 Garibaldi L. A., I. Steffan-Dewenter, C. Kremen, J. M. Morales, R. Bommarco, S. A.

329 Cunningham, L. G. Carvalheiro, N. P. Chacoff, J. H. Dudenhöffer, S. S. Greenleaf, A.

330 Holzschuh, R. Isaacs, K. Krewenka, Y. Mandelik, M. M. Mayfield, L. A. Morandin, S. G.

331 Potts, T. H. Ricketts, H. Szentgyörgyi, B. F. Viana, C. Westphal, R. Winfree \& A. M.

332 Klein. 2013. Wild pollinators enhance fruit set of crops regardless of honey bee 333 abundance. Science 339, 1608-1611.

334 Gathmann, A., and Tscharntke, T. 2002. Foraging ranges of solitary bees. Journal of Animal $335 \quad$ Ecology $71,757-764$.

336 Grace, J. B. 2006. Structural equation modeling and natural systems. Cambridge Univerisity 337 Press, New York. 365 pp. 
338 Griffin, J., E. O'Gorman, M. Emmerson, S. Jenkins, A. M. Klein, M. Loreau \& A. Symstad.

339 (2010) Biodiversity and the Stability of Ecosystem Functioning. Biodiversity, Ecosystem

340 Functioning, and Human Wellbeing (eds S. Naeem, D. E. Bunker, A. Herctor, M. Loreau

$341 \quad \&$ C. Perrings) pp. 78-93 Oxford University Press. New York.

342 Gurevitch, J., Curtis, P.S. \& Jones, M.H. (2001). Meta-analysis in ecology. Advances in

$343 \quad$ Ecological Research 32, 199-247

344 Grytnes, J. A., and McCain, C. M. 2007. Elevational trends in biodiversity. In: S.Levin (ed.)

345 Encyclopedia of biodiversity. Elsevier, Inc. pp. 1-8.

346 Hall. Whittaker, J. 1990. Graphical models in applied multivariate statistics. John Wiley \& Sons.

347 Hector, A., Y. Hautier, P. Saner, L. Wacker, R. Bagchi, J. Joshi, M. Scherer-Lorenzen, E.

348 M. Spehn, E. Bazeley-White, M. Weilemann, M. C. Caldeira, P. G. Dimitrakopoulos, J. A.

349 Finn, K. Huss-Danell, A. Jumpponen, C. P. H. Mulder, C. Palmborg, J. S. Pereira, A. S. D.

350 Siamantziouras, A. C. Terry, A. Y. Troumbis, B. Schmid \& M. Loreau. 2010. General

351 stabilizing effects of plant diversity on grassland productivity through population

352 asynchrony and overyielding. Ecology 91, 2213-2220.

353 Isbell, F. I., H. W. Polley, and B. J. Willsey. 2009. Biodiversity, productivity and the temporal

354 stability of productivity: patterns and processes. Ecology Letters 12:443-451.

355 Johnson, R. A. and W. Dean. 2002. Applied multivariate statistical analysis. -Prentice

356 Kim, S.H. and Yi, S. 2007. Understanding relationship between sequence and functional

357 evolution in yeast proteins. Genetica $131,151-156$.

358 Kim, S.H. and Yi, S. 2006. Correlated asymmetry between sequence and functional divergence

359 of duplicate proteins in Saccharomyces cerevisiae . Molecular Biology and Evolution 23,

$360 \quad 1068-1075$. 
361 Lázaro, A. and O. Totland. 2010. Local floral composition and the behaviour of pollinators:

362 attraction to foraging within experimental patches. Ecological Entomology 35, 652-661.

363 Loreau, M. 2010. Linking biodiversity and ecosystems: towards a unifying ecological theory.

364 Philosophical Transactions of Royal Society B 365, 49-60.

365 MacArthur, R. 1955. Fluctuations of Animal Populations and a Measure of Community

366 Stability. Ecology 36, 533-536.

367 Maestre F.T., M. A. Bowker, C. Escolar, M. D. Puche, S. Soliveres, S. Maltez-Mouro, P. García-

368 Palacios, A. P. Castillo-Monroy, I. Martínez \& A. Escudero. 2010. Do biotic interactions

369 modulate ecosystem functioning along stress gradients? Insights from semi-arid plant and

370 biological soil crust communities. Philosophical Transactions of the Royal Society B:

$371 \quad$ Biological Sciences 365, 2057-2070.

372 Manly, B.F.J. 1997. Randomization, bootstrap, and monte carlo methods in biology. Chapman \& $373 \quad$ Hall, London

374 Minckley, R. L., W. T. Wcislo, D. Yanega, and S. L. Buchmann. 1994. Behavior and phenology 375 of a specialist bee (Dieunomia) and sunflower (Helianthus) pollen availability. Ecology 75, $376 \quad 1406-1419$.

377 Moeller, D. 2004. Facilitative interactions among plants via shared pollinators. Ecology 85, $378 \quad 3289-3301$.

379 Müller, A, S. Diener, S. Shnyder, K. Stuts, C. Sedivy \& S. Dorn. 2006. Quantitative pollen 380 requirements of solitary bees: implications for bee conservation and the evolution of bee381 flower relationships. Biological Conservation 130, 604-615.

382 Oksanen, J., F. G. Blanchet, R. Kindt, P. Legendre, P. R. Minchin, R. B. O'Hara, G. L. Simpson, 383 P. Solymos, M. H. H. Stevens, and H. Wagner. 2013. vegan: Community Ecology 
Potts, S. G., B. Vulliamy, A. Dafni, G. Ne'eman, C. O’Toole, S. Roberts \& P. Willmer. 2003.

386 Response of plant-pollinator communities to fire: changes in diversity, abundance and

387 floral reward structure. Oikos 101, 103-112.

388

389

390

391

392

393

394

395

396

397

398

399

400

401

402

403

404

405

406

R Core Team 2013. R: A language and environment for statistical computing. R Foundation for Statistical Computing, Vienna, Austria. URL http://www.R-project.org/.

Richards, S. A. 2005. Testing ecological theory using the information-theoretic approach: examples and cautionary results. Ecology 86, 2805-2814.

Rosenthal, R. 1991. Meta-analysis procedures for social research. -Sage Publications, Newbury Park, CA.

Roulston, T. H. and Goodell, K. 2011. The role of resources and risks in regulating wild bee populations. Annual Revew of Entomology 56: 293-312.

Rundlöf, M., A. S. Persson, H. G. Smith, and R. Bommarco. 2014. Late-season mass-flowering red clover increases bumble bee queen and male densities. Biological Conservation 172, 138-145.

Sargent, R. D. and Ackerly, D. D. 2008. Plant-pollinator interactions and the assembly of plant communities. Trends Ecology and Evolution 23, 123-130.

Shipley, B. 2000. Cause and correlation in biology. A user's guide to path analysis, structural equations, and causal inference. Cambridge University Press.

Shipley, B. 2013. The AIC model selection method applied to path analytic models compared using a d-separation test. Ecology 94, 560-564.

Tilman D., P. B. Reich \& J. M. H. Knops. 2006. Biodiversity and ecosystem stability in a decadelong grassland experiment. Nature 441, 629-632. 
407 Tilman, D. 1999. Diversity by default. Science 283, 495-496.

408 Vázquez, D. P., S. B. Lomáscolo, M. B. Maldonado, N. P. Chacoff, J. Dorado, E. L. Stevani, and

409 N. L. Vitale. 2012. The strength in plant-pollination interactions. Ecology 93, 719-725.

410 Westphal, C., I. Steffan-Dewenter, and T. Tscharntke. 2009. Mass flowering oilseed rape

411 improves early colony growth but not sexual reproduction of bumblebees. Journal of

$412 \quad$ Applied Ecology 46, 187-193.

413 Williams, N. M. and C. Kremen. 2007. Resource distribution among habitats determine solitary

414 bee offspring production in a mosaic landscape. Ecological Applications 17, 910-921.

415 Williams, N. M. and V. J. Tepedino. 2003. Consistent mixing of near and distant resources in

416 foraging bouts by the solitary mason bee Osmia lignaria. Behavioral Ecology 14, 141-149.

417 Zar, J.H. 1999. Biostatistical Analysis. -Prentice Hall, Upper Saddle River, NJ

418 Zurbuchen, A., S. Cheesman, J. Klaiber, A. Muller, S. Hein, and S. Dorn. 2010. Long foraging

419 distances impose high costs on offspring production in solitary bees. Journal of Animal

$420 \quad$ Ecology $79,674-681$. 
421 Figure 1. Models evaluating the effect of flower diversity and other ecological factors on the

422 reproductive variables of different bee species of the 14 study sites. a) Complete model. b)

423 Nested models generated by removing variables with non-significant effects or small path

424 coefficients that were non-significant. Model 2 was selected by $\Delta$ AIC for all bee species.

425

426 Figure 2. Box-plot summarizing the path coefficients of model 2 (see Fig. 1) for the seven bee 427 species studied here. In each box plot, the middle line indicates median, box limits are the first 428 and third quartiles, whiskers indicate most extreme points $\leq 1.5$ times the interquartile range, and 429 circles indicate outliers of the seven path coefficients of the corresponding effect. Model 2 430 describes the effect of flower diversity (estimated using flower richness), temporal stability of 431 flower production along the flowering season (estimated as the inverse of the coefficient of 432 variation of the weekly flower abundance mean), and elevation ( $\mathrm{m}$ above sea level) on three bee 433 reproductive variables: "Average cells", the average number of brood cells per nest per site;

434 "Total cells", the total number of brood cells per site; and "Total nests", the total number of nests 435 per site. The ordinates represent the path coefficients; the abscissa represent the effect of the 436 above ecological variables on bee reproductive variables. Blue error bars are the ninety-five 437 percent confidence limits of path coefficients obtained from bootstrap sampling of the 438 distribution of path coefficients. 


\section{Figure 1 (on next page)}

Figure 1 
a Model 1

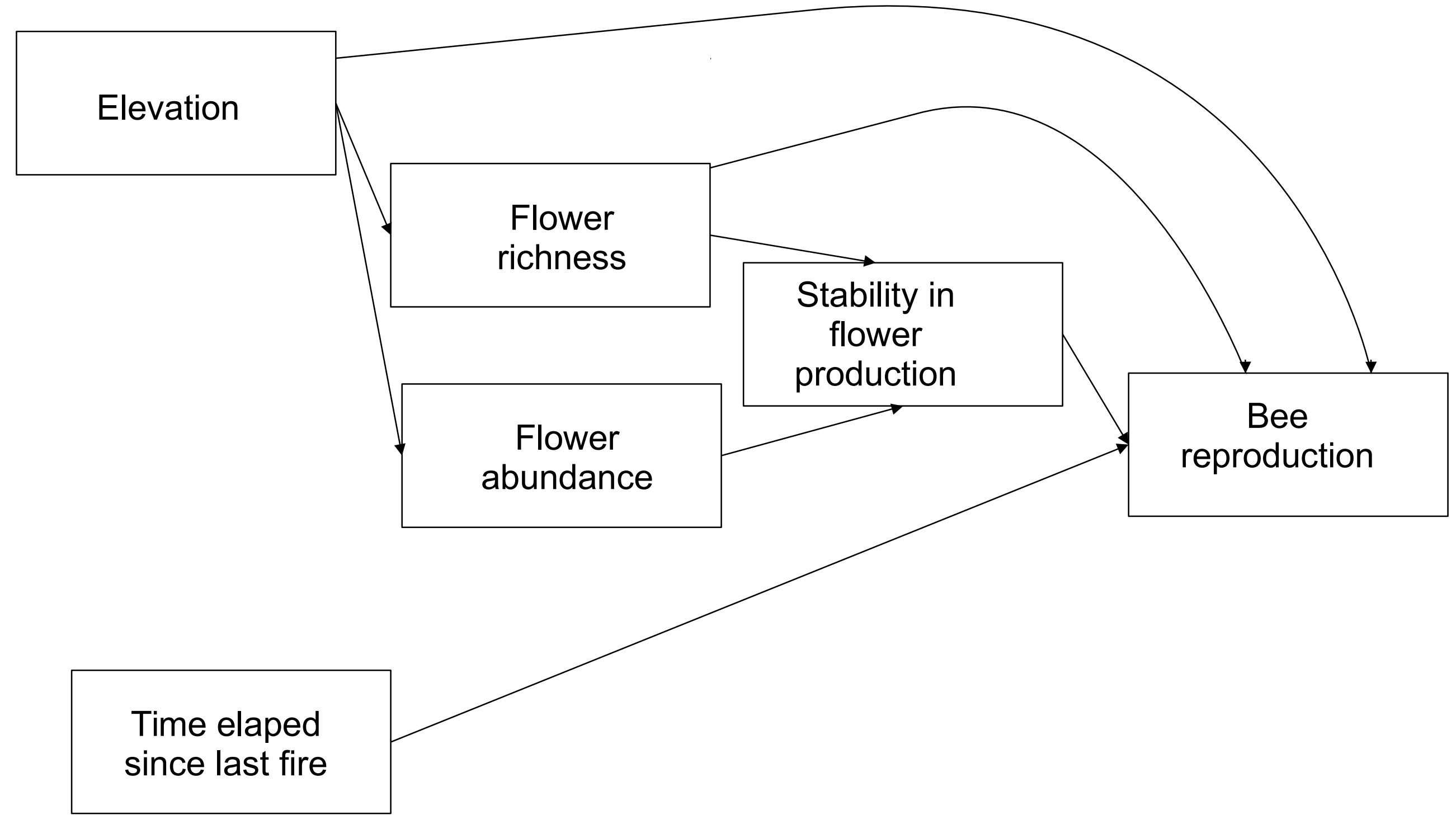


b Model 2

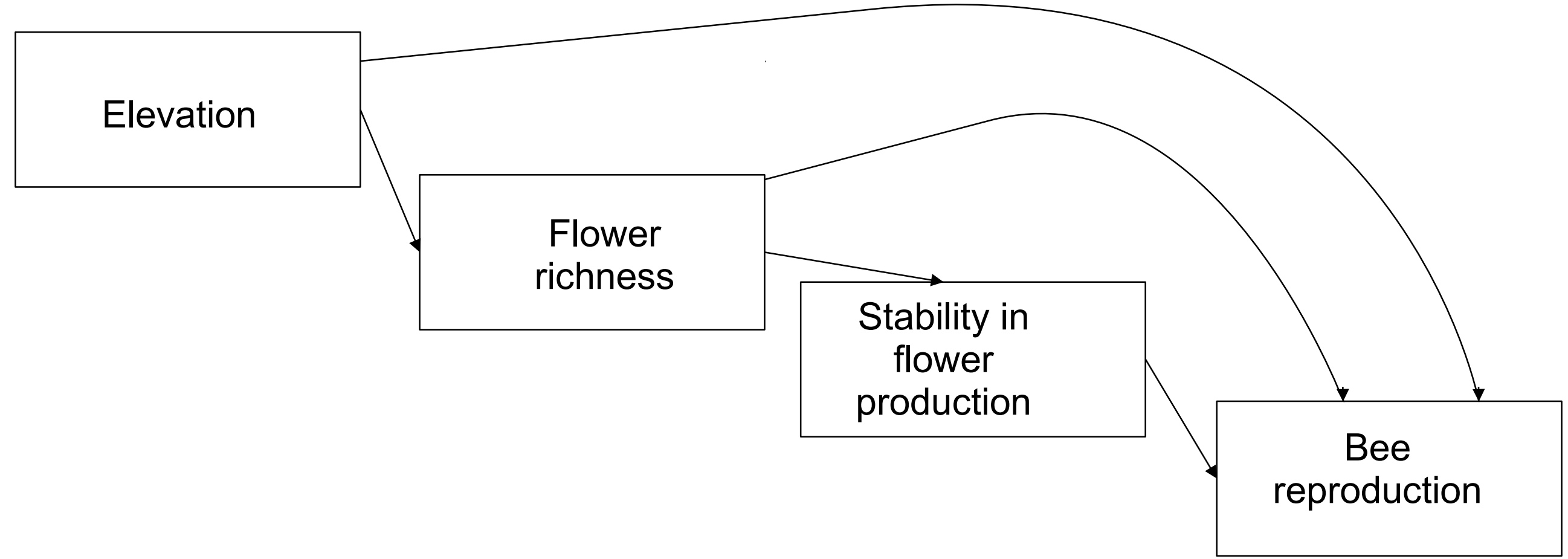




\section{Figure 2 (on next page)}

Figure 2 


\section{Table 1 (on next page)}

Table 1

Number of nests per species. We used in this study the species that had more than 30 nests. 
1 Table 1. Number of nests per species. We used in this study the species that had more than 30 2 nests.

3

\begin{tabular}{lc}
\hline Bee species & Occupied trap nests \\
\hline Anthidium andinum Jörgensen & 6 \\
Anthidium decaspilum Moure & 54 \\
Anthidium rubripes Friese & 31 \\
Anthidium vigintipunctatum Friese & 39 \\
Megachile sp. A & 222 \\
Megachile sp. C & 17 \\
Megachile ctenophora Holmberg & 74 \\
Mourecotelles triciliatus Toro y Cabezas & 3 \\
Trichothurgus laticeps Friese & 59 \\
Xylocopa ordinaria Smith & 88 \\
Xylocopa splendidula Lepertier & 5 \\
\hline
\end{tabular}




\section{Table 2 (on next page)}

Table 2 
1 Table 2. Path coefficients of Models 1 and two for community bee reproduction.

2

\begin{tabular}{clcc}
\hline model & \multicolumn{1}{c}{ variables } & Path coefficients & p-value \\
\hline 1 & & & \\
& Elevation $\rightarrow$ Flower richness & 0,39 & 0,15 \\
& Elevation $\rightarrow$ Flower abundance & $-0,51$ & 0,06 \\
& Flower richness $\rightarrow$ Stability & $-0,54$ & 0,04 \\
& Elevation $\rightarrow$ Total brood cells & $-0,59$ & 0,03 \\
Elevation $\rightarrow$ Total nests & $-0,57$ & 0,04 \\
Flower abundance $\rightarrow$ Total brood cells & 0,26 & 0,43 \\
Flower abundance $\rightarrow$ Total nests & 0,24 & 0,48 \\
Flower richness $\rightarrow$ Total brood cells & 0,27 & 0,80 \\
Flower richness $\rightarrow$ Total nests & 0,38 & 0,23 \\
Stability $\rightarrow$ Total brood cells & 0,35 & 0,35 \\
Stability $\rightarrow$ Total nests & 0,30 & 0,35 \\
Time elapsed since last fire $\rightarrow$ Total brood cells & 0,35 & 0,28 \\
Time elapsed since last fire $\rightarrow$ Total nests & 0,45 & 0,14 \\
\hline
\end{tabular}

3 


\section{Table $\mathbf{3}$ (on next page)}

table 3 
1 Table 3. Correlation coefficients between effect of flower diversity on pollinator reproduction

2 and bee generalization.

\begin{tabular}{llccc}
\hline \multicolumn{1}{c}{ Generalization index } & \multicolumn{1}{c}{ Reproductive variable } & $\begin{array}{c}\text { Correlation } \\
\text { coeficient }(r)\end{array}$ & $p$-value & $N$ \\
\hline degree & Average number of cells per nest & -0.21 & 0.66 & 7 \\
degree & Total number of cells per site & 0.42 & 0.35 & 7 \\
degree & Total number of nests per site & 0.39 & 0.39 & 7 \\
Simpson's diversity index & Average number of cells per nest & 0.14 & 0.78 & 7 \\
& & & & 7 \\
Simpson's diversity index & Total number of cells per site & 0.46 & 0.30 & 7 \\
& & & & 7 \\
Simpson's diversity index & Total number of nests per site & 0.28 & 0.55 &
\end{tabular}

3 